\title{
An Overview of General Human Behavior under a Disaster Situation
}

\author{
Bilintoh Mumuni Daniel Nashiru, Zhang Jun \\ University of Science and Technology of China (USTC), State Key Laboratory of Fire Science (SKLFS) \\ *Correspondence: belintonash@gmail.com, junz@ustc.edu.cn
}

\begin{abstract}
When a disaster happens, and emergency caution sounds, it is anticipated that people will stay levelheaded, composed, and collected. Being calm amid a fatal event is exceptionally valued and definitely enhances your survival probabilities. But detailed reports and inadequate research accessible propose that persons under danger can behave in a manner that put them and others in more risk. This paper explores a few of the unconstructive behaviors which can occur amid predicaments and interventions to mitigate them.

Keywords:

Panic: individuals flight because of abrupt subjective or influenced fear, individuals are moving imprudently. Crush: individuals are moving and a stop happens by external impacts for example barriers which make persons press against each other. Stampede: individuals moving without likelihood of stopping. Flight: individuals leaving a place in a normal manner. The death happens by the second order events. For example, getting hit by debris
\end{abstract}

\section{Introduction}

Becoming composed amid a horrifying occurrence is exceptionally cherished and enhances the survival chances. But anecdotal reportage and the few psychological explorations accessible recommend that when persons are under threat, they behave in a particular manner that puts them and other persons in danger. A disaster is a severe disruption that devastates the affected community operations, financial, human, and material destructions, which surpasses the community's ability to coping using its assets. Disasters are perceived as the outcomes of risks that are managed inappropriately. The risks are the blend of both vulnerability and peril products. These disasters are categorized into two types; i.e., natural disasters and human mistakes.

Natural disasters are processes of mega-scale geologic events, for example, floods, tsunamis, earthquakes, floods, and volcanic eruptions happening sporadically amid the geologic period. Human activities have an impact on the earth that are contrasted to or more significant than these natural catastrophes. There are likewise human practices, for example, aviation mishaps, fire calamities, transport tragedies, nuclear power calamities, and space exploration disasters. This article explores some survivor encounters from several disaster circumstances and emergency evacuation.

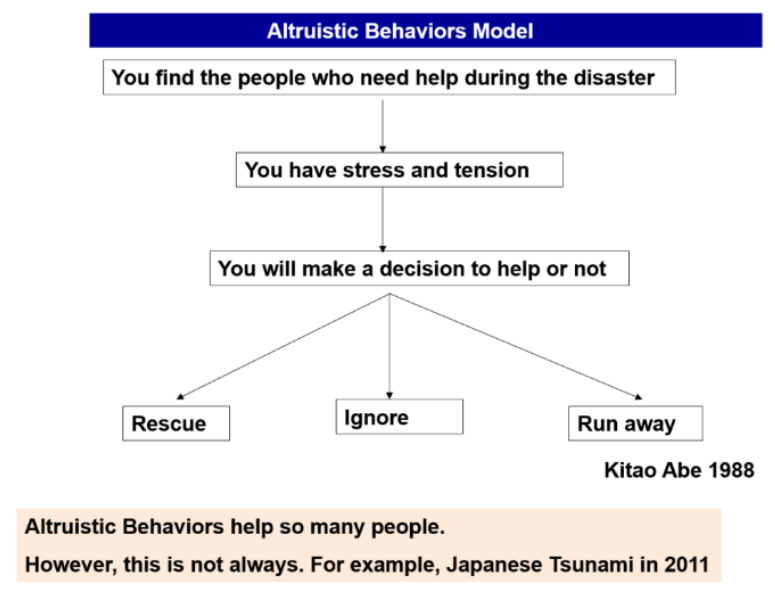

What Behaviors Do People Adopt Amid a Disaster?

Individuals can behave suitably amid an emergency. In proper circumstances, in the absence of pressure on assets or time, composed systematic response(s) is/are prone. In situations that are more chaotic prompt thinking and operational actions can result in positive practices. For instance, amid the January 2012 cruise ship of Costa Concordia that sank, eyewitnesses noted several occurrences of practical conducts. Some commuters utilized their iPhone applications in working out their position on the ship, whereas others used sheets in reaching the next dock for safety. But research proposes that just ten to twenty-five percent of persons in a crisis will adapt quick and practical actions. During an emergency, $65 \%$ to $80 \%$ of victims are indecisive and behave in a surprised and panicky way. Some emergency victims depict severe

[Received 16 Jan 2020; Accepted 19 March 2019; Published (online) 31 March 2020] Publisher's Note: RCLSS stays neutral regard to jurisdictional claims published maps (c) (1) 
maladaptive conduct, for example, mania, crying, and paralyzing anxiety. These behavior types were witnessed onboard Costa Concordia, with persons inertly standing or running pointlessly on the stairs up and down. So why do these behavior types happen? Many authors recognized the benchmark for identifying calamities as the following;

- $\quad$ The magnitude of the crisis determined by the lives or assets lost or degree of failure of the cultural framework.

- As per the organization's inactions, as per national governments assistance,

\begin{tabular}{ll} 
Evacuation Behavior & \multicolumn{1}{c}{ Population Attributes } \\
\hline Non-adaptive & $\begin{array}{l}\text { Vulnerability, traditional belief, low } \\
\text { danger perception of disaster, panic/stress }\end{array}$ \\
& $\begin{array}{l}\text { Previous disaster experience, disaster } \\
\text { training, ownership of farms/livestock, } \\
\text { Adaptive }\end{array}$ \\
ownership of valuables \\
Altruistic & $\begin{array}{l}\text { Social concern } \\
\text { Leader-following }\end{array}$ \\
\hline
\end{tabular}

Panic as a Human Behavior Adopted Under a Disaster Situation

Panic is defined as a strong sentiment of fear that inhibits reasonable thinking. An unexpected fear sensation that is intense and overpowers or avert and rational thinking. Substituting it with overwhelming anxiety feelings and agitated distress likened with animalistic flight or fight response. Dread might happen singularly in persons or illustrate suddenly in big masses as mass dread. Other people might be harmed as a result of panicking and fleeing without thinking. Staying composed is worse because individuals are not walking away from the disaster's devastation and damage. One typical perceive myth is that persons create an impossible, irrational fear during calamities. Hence this fear becomes transmittable, sprain it to others, and causing individuals to escape without rational and in a disordered method that could harm those around them.

This model outlines victim's movement amid emergency as inept objects that operate illogically, and who do not follow collective guidelines during emergency evacuation ${ }^{[1,2]}$. This behavior nature might be portrayed when persons become knowledgeable of crisis due to many persons endeavoring to leave using a similar restricted path. The panic model depicts how clumsy behavior can result in massive physical influences and fear that people have and arise in crowd crushing. Though this behavior type can happen in a crisis setting, it can be mostly refuted if individuals are provided with usable data concerning an occurrence. This model has been challenged because sometimes people can depict rational behaviors when they are composed amid an emergency. The panic model is critiqued because of the bounded rationality theory. This hypothesis contends that persons can make a logical decision amid crisis, though with

restricted data and cognitive assets. As a result, this might trigger so evidently non-supportive mass conducts. A typically held disaster myth is that individuals create an impossible and irrational fear during an emergency. Hence this fear becomes infectious, spreading to other persons, instigating individuals to begin fleeing without reasoning, and in a chaotic way and can harm those around them.

\section{Other Collective Behaviors}

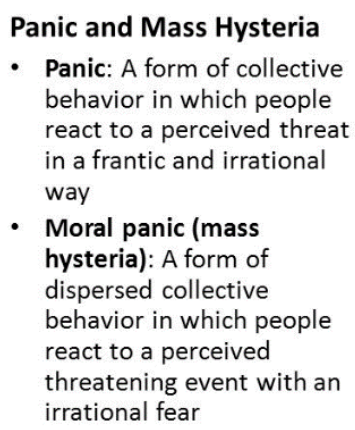

- Panic: A form of collective behavior in which people react to a perceived threat in a frantic and irrational way

- Moral panic (mass hysteria): A form of dispersed collective behavior in which people react to a perceived threatening event with an irrational fear

\author{
Disasters \\ - Disaster: An event that \\ causes extensive harm \\ to people and property \\ - Types of disasters: \\ - Natural disasters \\ - Technological disasters \\ - Intentional disasters
}

\section{Memory Failures as a Human Behavior Adopted Under a Disaster Situation}

The brain is structured to process data that will be beneficial at a future period and allowing the rest to occur unnoticed. As information is apparent, it is hence automatically kept in sensory memory and unbidden. Dissimilar to other memory types, the sensory memory cannot be extreme using rehearsal. Threat results in memory loss and some memory loss are typical occurrence to everyone. For instance, when driving a car and become unaware of what to do. In 2010 amid a house fire, a woman failed to state to firefighters that in the burning house her grandson was asleep since she had forgotten he came to visit. The same case comprises of a nun who never recalled the school location where she was employed after calling the fire unit amid the fire. Disaster fatalities have remembrance issues because the body discharges excessive stress hormone amounts, which impact other brain parts accountable for memory processing. Whichever the case, it is apparent that memory loss amid calamities can affect individuals to disregard how disaster equipment is used or how tragedy methods are followed.

\section{Freezing as a Human Behavior Adopted Under a Disaster Situation}

The freezing conduct is most simply defined by blood pressure changes and time lengths in a crouching position. However, it is likewise known to result in transformations, for example, breath shortness, enhanced heart rate, sweating, or choking feeling ${ }^{[3,4]}$. But because it is challenging to quantify these sympathetic reactions to dread stimuli, investigations are mostly confined to necessary crouching times. Stimuli response is mainly termed as fight or flight; however, more entirely characterized a freeze, conflict, or flight. Also, 
freezing is known to happen afore or after fight or flight reactions. Amid calamities freezing, likewise termed as cognitive paralysis is typically perceived as persons struggling to produce new suitable conducts. For instance, amid the 1989 Hillsborough football stadium calamity, one eye witness stated observing a policeman ignoring a girl getting crushed to death. The eyewitness narrated how the policeman stood there in dismay and looked blanket although one of the eyewitnesses shouted at him. Same stunning conduct has been witnessed in several calamities circumstances from fires to flooding.

\section{Denial as a Human Behavior Adopted Under a Disaster Situation}

Among the principal cause, individuals fail in responding to danger is due to entering the denial state. Past encounters of false alarms or wrong catastrophe warnings can trigger persons, quite reasonably in believing that actions are not required. For instance, in Ephrata, Pennsylvania, in 1990, eighty-two percent of those involved in the chemical fire stopped to evacuate. Founded on prior encounters, employees believed that they wouldn't be bluntly affected by the fire. Nevertheless, some persons stated later that they approached the fire that their jackets had burn voids. Denial mostly likely occurs if persons do not believe the calamity warning source. In the Costa Concordia accident, the warning was not taken seriously by most commuters because it was a dancer to raised and caution and people though the dancer was doing theatrics. Another reason why individuals fail to react to catastrophe indications is not wanting to diverge from what others are performing. Humans are a societal species and often emulate other individuals. If most individuals are not taking heed of cautionary indications, individuals will continue conforming to that behavior and following their lead irrespective of how hazardous it is. Amid a restaurant fire, diners kept on eating their food as if nothing was amiss. One customer even lamented how "uncomfortable it was becoming because of the fire engines sirens and smoke." (Cocking, Drury, \& Reicher, 2009)

Another reason the person ignores the threat is that they are unaware of what to do. In everyday life, several pre-planned conducts occur which we draw on. For instance, we are aware of proper etiquette when invited to an elegant dinner party as contrasted with how we behave amid a fast food restaurant meal. When individuals encounter a novel circumstance, for example, being in a disaster, they lack an available schema and so they are compelled to produce a new behavior. In constant, developing new response is realistic, but under coercion, it enhances more challenges because of time demands. Hence in a calamity, we see whichever;

(i) No manner produced, so individuals seem to freeze

(ii) Wrong or stereotypical conduct happening when persons utilized pre-existing, however inaccurate schema.

\section{Stereotypical Behaviors as a Human Behavior Adopted Under a Disaster Situation}

The stereotype is defined as monotonous body movement in variance that functions as no social function. A stereotype is a tedious or ritualistic movement, expression, or posture. Typecasts might be basic movements, for example, boy rocking or composite like self-caressing, legs crossing, crossing and walking in place. Always kids with autism are involved in these repetitive, confined, and stereotyped behavior patterns. Stereotypic conduct can adopt several unusual forms. Occasionally amid calamities, individuals can avert freezing by getting involved in a pre-existing scheme. Though it is less cognitively demanding to use composed actions, it can outcome in some less than exemplary behaviors. For instance, amid catastrophe when clearing from buildings, individuals might pass over the crisis exit as they utilize their typical pre-scheduled exit path.

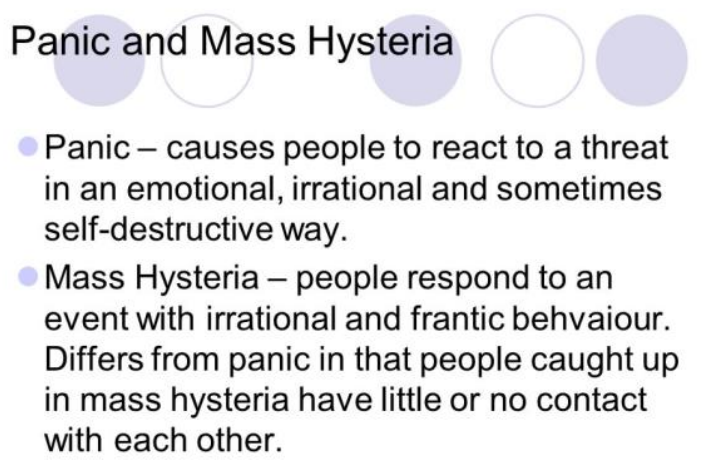

\section{Inappropriate Behaviors Adopted Under a Disaster Situation}

Similar to adopting stereotypical conducts, individuals in threat circumstances can likewise make bad decisions that result in incorrect actions. Calamities are time-pressured, and casualties can be confronted with massive vague, partial, and novel data. Experimental investigations have precisely depicted that under these conditions types individuals are more likely to make judgment mistakes. Unsuitable decisions examples amid calamities are typical. For instance, amid the March 2011 Japanese earthquake, BBC footage depicted Individuals in a superstore fleeing to hoard alcohol bottles from breaking than doing the appropriate earthquake drill ${ }^{[5]}$. A study that investigated civilian admissions to crisis rooms in Israel in 1990 when Iraq invaded Kuwait discovered the effects improper behavior can have on survival. The study established that of the 1,059 persons who registered to crisis rooms just two hundred and thirty-four twenty-two percent of injured persons that were the direct outcome of missile outburst. The lingering seventy-eight percent of admissions 
was the outcome of improper conduct amid the missile attack. For instance, two hundred and thirty patients had auto-infused atropine exclusive of chemical agent revelation. An advance forty patients had wounded themselves while fleeing into their adjacent rooms and seven throttled due to leaving the filter closed on them as masks ${ }^{[6]}$.

\section{SAFETY DOMAIN ASSESSMENT}

Arousal: self harm actions/plan, specific / directive perceptual disturbances, extreme anxiety, constant panic, not able to calm / comfort, active mania, severe withdrawal / catatonia

Behavior: no sleep or rest, pacing incessantly, bizarre behaviors, brought by security, fighting, yelling, intrusive, "out of control", mute, constant crying

Cognition: not able to appreciate reality of circumstance, generally confused, deny obvious needs, markedly deficient memory or attention, markedly disturbed judgment, essentially noncommunicative, hopeless/helpless

\section{Holing it Together until Rescue}

One exciting opinion of disaster casualty is that some have the capability of quickly and effectively operating under danger; however, at rescue point become confused. For instance, Lauren Elder outlived an airliner accident on the High Sierra, strolled on a foothill and via the wilderness to an urban center. After arriving in the clinic, she was unable to walk and fell into lethargy. The same collapse is witnessed in survivors of Chilean mine who behaved rationally while stuck concealed however befell mesmerize and bemused upon salvage. Same cognition functioning collapses have been seen in firefighters after a replicated exploration and liberation activities at Fleetwood Nautical School ${ }^{[8,16]}$.

\section{Inferences and Intercessions of Behaviors Adopted Under a Disaster Situation}

Guaranteeing that individuals will behave correctly amid a crisis is challenging, and several variables can impact how individuals react ${ }^{[15,17]}$. Past encounters, gender, educational level, as are some of the elements which determine how suitable persons react. Situational, for example, the intensity of victims' encounters is crucial. Some individuals might after an earthquake occurring for several hours be trapped under rubble, while others away from the epicenter might flee without injury.

Underneath are some crucial remarks which might aid individuals operating in crisis. Also, suggestions have been noted in which might enhance suitable behaviors amid lifethreatening occurrences and so enhance survival:

$>\quad$ The emergency services workforce should be acquainted that they will recognize a marked difference in persons conduct reaction to risk. Intriguingly some have perceived that persons who seem confident and in the domination of their everyday life can become more prone to fall separately amid catastrophe.

$>\quad$ Wrong fears and unsuitable info should be averted at all expense as they decrease adherence with forthcoming calamity alarms.

$>\quad$ Messages on emergency warnings should originate from a trustworthy informer in increasing the probability of trust.

$>\quad$ Individuals will often act in a comparable way to persons around them. It can become an actual problem in getting persons to evacuate, for instance, if people around them are not shifting. If a few persons are encouraged to begin behaving suitably, then others will probably follow suit.

$>\quad$ Creating a schema using a practical drill in crisis apparatus and processes can lessen freezing and prescribed conducts.

$>\quad$ Confidence can likewise be increased through training and as an outcome person are can keep their sentiments in assessment amid calamities. Decreased anxiety has similarly been depicted to enhance memory operative, and so causalities might be more probable to recall how to utilize apparatus and engage in tragedy exercises.

$>\quad$ Apprehension, as a result of the catastrophe, can enhance the discharge of cortisol, which is a stress hormone. Cortisol is referred to as impaired mental procedures, for example, memory. Nevertheless, cortisol can lessen with nutritional mediations, for instance, L-theanine, that's present in teas and sugar. Hence, the hypothesis that is required is sitting down to drink sweet tea to help in recovering might be real.

$>\quad$ The emergency workforce should be knowledgeable that persons can appear to be generally operating amid the calamity. But some persons might undergo a cognitive breakdown abruptly after salvage.

\section{Social defense theory}

A decade ago, ${ }^{[9,14]}$ has contended that personality variations can be understood in terms of tradeoffs among fitness costs and benefits: "Behavioral alternatives can be considered as tradeoffs, with a particular trait producing not unalloyed advantage but a mixture of costs and benefits such that the optimal value for fitness may depend on very specific local circumstances". SDT ${ }^{[10,13]}$ adopts Nettle's perspective and proposes that security and insecurity dispositions alike endow adaptive advantages that increase the likelihood of survival while also incurring distinct disadvantages that might hinder survival unless they are complemented by contributions from people with different attachment dispositions ${ }^{[11,12]}$.

\section{Conclusion}

This article illustrates how challenging it is to remain calm during an emergency situation. Several examples are given concerning human behavior in mass emergencies that further complicate the process of rescuing the disaster victims. 
Becoming composed amid a horrifying occurrence is [15]. exceptionally cherished and enhances the survival chances. But anecdotal reportage and the few psychological explorations accessible recommend that when persons are under threat, they behave in a particular manner that puts them and other persons in danger.

\section{References}

[1]. Cocking, C., Drury, J., \& Reicher, S. (2009). The Psychology of Crowd Behavior in Emergency Evacuations: Results from Two Interview Studies and Implications for the Fire and Rescue Services. The Irish Journal of Psychology, 30(1-2), 59-73.

[2]. Gonzales, L. (2003). Deep Survival: Who lives, who dies, and why: True Stories of Miraculous Endurance and Sudden Death. WW Norton \& Company.

[3]. Leach, J. (2004). Why People' Freeze 'in an Emergency: Temporal and Cognitive Constraints on Survival Responses. Aviation, Space, and Environmental Medicine, 75(6), 539-542.

[4]. Leach, J. (2005). Cognitive Paralysis in an Emergency: The Role of the Supervisory Attentional System. Aviation, Space, and Environmental Medicine, 76(2), 134-136.

[5]. Nettle's (2006, "Behavioral alternatives can be considered as tradeoffs p. 625

[6]. Tsachi Ein-Dor. (2014) Facing danger; 5: 1452

[7]. MSN news (2010).Woman forgot grandson in house fire. http://news.uk.msn.com/uk/articles.aspx?cpdocumentid=153701214. Retrieved July 09, 2012.

[8]. Robinson S. J., Sunram-Lea, S., Leach, J. and OwenLynch P. J. (2008) The effects of exposure to an acute naturalistic stressor on working memory, state anxiety and salivary cortisol concentration. International Journal on the Biology of Stress. 11(2), $115-121$

[9]. Elder, L. and Streshinsky, S. (1978). And I Alone Survived. New York: Thomas Congdon Books.

[10]. Guardian (2011). Chilean miners struggling with financial and psychological problems. http://www.guardian.co.uk/world/ 2011/aug/04/chileanminers- financial-

[11]. Leach, J. (1994). Survival Psychology. London: MacMillan Press Ltd.

[12]. ABC News. (2012). Cruise Ship Survivors Share Stories Both Harrowing and Hopeful.

http://news.yahoo.com/cruise-ship-survivors-sharestories-both-harrowing-hopeful195623964--abcnews.html. Retrieved July 09, 2012.

[13]. Fischer, H. W. (1994). Response to disaster: Fact Versus Fiction and Its Perpetuation: The Sociology of Disaster, New York and London: University Press of America.

[14]. Wood, P. (1970). In Canter, D. (1980). Fires and Human Behaviour. London: John Wiley \& Sons Ltd.
Newburn, T. (1993). Disaster and After: Social Work in the Aftermath of Disaster. Wiltshire: Cromwell Press Ltd.

[16]. Bickerman, L., Edelman, P., \& McDaniel, M. (1977). A model of Human Behaviour in a fire emergency.NBSGCR-78-120.National Bureau of Fire Protection.

[17]. Ripley, A. (2005). How to get out alive. Time, 65(18), 58-62 